\title{
Methods to Evaluate Rumen Protected Lysine for Dairy Cows
}

\author{
Essi Evans' ${ }^{1}$, Josh Lamont ${ }^{2}$, Helene Leclerc ${ }^{3}$ \\ ${ }^{1}$ Technical Advisory Services Inc., Bowmanville, Canada \\ ${ }^{2}$ Atlantic Dairy and Forage Institute, Fredericton Junction, Canada \\ ${ }^{3}$ Jefo Nutrition Inc, St. Hyacinthe, Canada \\ Email: essievans@sympatico.ca
}

Received 24 September 2015; accepted 23 October 2015; published 26 October 2015

Copyright (C) 2015 by authors and Scientific Research Publishing Inc.

This work is licensed under the Creative Commons Attribution International License (CC BY). http://creativecommons.org/licenses/by/4.0/

cc) (i) Open Access

\section{Abstract}

There are many rumen protected amino acid products available for dairy cattle feeding. However, feed formulation programs require values related to rumen solubility, rate of disappearance in the rumen and total tract digestibility and often such values are not available. In vivo testing procedures are complex, time consuming and expensive. This study was conducted to determine if a newrapid, lower cost in vitro method developed for feed ingredients could be applied to a rumen protected lysine product (DairynatLys-30 ${ }^{\circledR}$, Jefo Nutrition Inc). In vivo determination of the rapidly solubilized protein fraction, rate of degradation of the slowly solubilized fraction and total tract digestibility studies were compared to the in vitro method in use in many ingredient analysis laboratories for feed ingredients such as forages, protein supplements and grains. Results showed that the rapidly soluble fraction $(8.33 \%$ and $8.66 \%$ of total $\mathrm{N}$ for in vivo and in vitro methods) and rates of disappearance in the rumen $(2.64 \% / \mathrm{h}$ and $2.43 \% / \mathrm{h}$ for in vivo and in vitro procedures) compared favorably between the two methods for the rumen protected product. Total tract digestibility values were slightly higher $(84.4 \%)$ with the in vivo method used than with the in vitro method (75.9\%), and both are in the expected calculated range of digestibility of $80 \%$. In conclusion the in vitro method appears to be an acceptable alternative for evaluating rumen protected amino acids.

\section{Keywords}

Rumen Protected Amino Acids, Lysine, In Vitro Testing

\section{Introduction}

Formulating diets on the basis of amino acids rather than protein is rapidly becoming standard practice in dairy 
cattle nutrition. There is pressure to optimize protein and amino acid use in dairy cows as excess nitrogen (N), resulting from over formulating the protein of the diet, is a burden to both the environment and to the cow. With respect to the animals, cows must consume energy to convert excess amino acids to urea for elimination. As to the environment, many jurisdictions have introduced strict guidelines that limit the use of manure application upon land. Diets need to be formulated in order to reduce oxidation of amino acids to the extent possible, by feeding the correct amounts of amino acids whenever possible.

Lysine is an essential amino acid needed for the synthesis of protein in growth, milk production, tissue maintenance and repair and gestation. Lysine is additionally a constituent of carnitine, a compound needed to transport fat into cellular structures [1]. Animal by-products are rich sources of lysine, while vegetable sources are not.

To take advantage of advanced formulation technology, the formulator must be able to predict the amount of amino acids derived from feed ingredients. Animal tests required to assign the values to nutrients can be expensive and time-consuming and many suppliers do not provide the values needed. A new laboratory method for the determination of rate of digestion and protein digestibility have been published and adopted by feed ingredient analysis laboratories in North America [2]. To our knowledge, results have not been compared to biological tests for products such as this one. If this method can be applied to the analyses of rumen protected amino acids, then there would be substantial savings in cost, and much-needed uniform results could be obtained. This study was conducted to generate values for a rumen-protected lysine product (Dairynat Lys-30 ${ }^{\circledR}$, Jefo Nutrition Inc), and to determine if the newer laboratory method can be used to replace animal testing for this product and similar products.

\section{Materials and Methods}

\subsection{Description of Test Product}

The product tested was rumen protected lysine (DairynatLys-30 ${ }^{\circledR}$ ) developed by Jefo Nutrition, Inc. St. Hyacinthe, QC, Canada. The product contained 30\% lysine from lysine HCL, protected in a lipid matrix.

\subsection{Animal Studies}

The following animal testing procedures were conducted by the Atlantic Dairy and Forage Institute, Fredericton Junction, NB, Canada. Cows used in the evaluations were handled in accordance with guidelines as outlined by FASS [3]. Cows were housed in stanchion stalls and allowed ad-libitum access to feed. Feed was mixed and allocated twice daily at approximately 600 hours (h) and $1800 \mathrm{~h}$. The cows were milked twice daily at approximately $700 \mathrm{~h}$ and $1700 \mathrm{~h}$. The ingredient and nutrient composition of the diet given to the cows is provided in Table 1.

\subsubsection{Determination of Ruminal Rate of Disappearance of Lysine from Rumen Protected Lysine} Two rumen cannulated mid-lactation Holstein cows were used in this study. The procedure was conducted over

Table 1. Composition of the diet used during the study period (\% of dry matter, DM).

\begin{tabular}{cccc}
\hline Ingredient Composition & \% of DM & Nutrient Composition & \% of DM \\
\hline Grass silage & 34.68 & Dry matter & 51.8 \\
Corn silage & 15.31 & Crude protein & 16.7 \\
Canola meal & 20.38 & Acid detergent fiber & 23.2 \\
Barley grain & 18.72 & Neutral detergent fiber & 37.4 \\
Corn grain & 7.25 & Ash & 8.81 \\
Premix & 2.34 & Fat & 3.93 \\
Fat & 0.60 & & \\
Limestone & 0.38 & & \\
Yeast & 0.21 & & \\
Urea & 0.13 & & \\
\hline
\end{tabular}


two consecutive days. Three samples of Lys 30 from 3 different manufacturing lots were studied, and provided to both cows. Analyses were conducted as suggested by Vanzant et al. [4] with the exception of grinding. Samples were incubated in the prilled form in which they would normally be included in the diet. The ingredient samples were placed in the nylon bags (pore size 53 microns) in the form received. For each sample, 15 replicates, weighing approximately 6 g each were incubated in the rumens of each of the cows (30 bags in total/ sample). Samples were incubated in the ventral sac of the rumen,and were sequentially added so that they could all be removed at the same time. Three samples were each incubated for 2, 6, 12, 18 and $24 \mathrm{~h}$. Residues were washed in tepid water five times for 3 minutes using a washing machine, dried at low temperature in a forced air oven and dry matter determined by sample, incubation time, and cow. Samples were then pooled by time within cow each day to insure sufficient sample for further analysis.

As lysine was the only source of $\mathrm{N}$ in the ingredient, $\mathrm{N}$ determination was used to estimate rate of loss of lysine at each time point. Lysine contains $19.15 \%$ N, and lysine was calculated as 5.22 times N. Samples of the original materials were likewise included for analysis.

Rates of disappearance in the rumen were determined as the natural log of the amount remaining regressed against time. The intercept provides the amount that is rapidly released in the rumen (A fraction) and the rate function generated represents the rate for lysine disappearance (solubilization) in the rumen (Kd).

\subsubsection{Determination of Intestinal Digestibility}

Due to the complexity of the animal testing and the labor involved, a single sample of DairynatLys- $30^{\circledR}$ was evaluated, using 6 cows. Two cows served as untreated controls, two acted as positive controls and two were used to evaluate Dairynat Lys-30 ${ }^{\circledR}$ ).

Blood was drawn at approximately $1 \mathrm{~h}$ before and again at $1 \mathrm{~h}$ after feeding to serve as an estimation of the baseline level of lysine for each cow. Immediately thereafter, the two positive control cows received an abomasal $(1.2 \mathrm{~L})$ infusion containing $50 \mathrm{~g}$ of lysine in the form of lysine $\mathrm{HCl}$ over a 30 minute period. Similarly, the two treatment cows received a solution containing $50 \mathrm{~g}$ of lysine in $1.2 \mathrm{~L}$ of water from the test product placed through the rumen and into the abomasum over a 30 minute period. The untreated control cows received water only $(1.2 \mathrm{~L})$ over the same time period.

Blood was then drawn from all 6 cows at 2, 4, 6, 8 and 10 hours after feeding, and these times were after the infusion was complete. All blood samples were obtained by tail vein puncture. Blood $(7-10 \mathrm{ml}) \mathrm{l}$ was collected into tubes containing anticoagulant. Blood was centrifuged at $3000 \times \mathrm{g}$ for 15 minutes to separate the plasma. Plasma was stored frozen $\left(-32^{\circ} \mathrm{C}\right)$ until submitted for analysis of free lysine. Analyses were conducted by the University of Montreal Laboratoire de Chromatographie Faculté de médecinevétérinaire.

\subsection{Laboratory Analyses}

Three samples of DairynatLys- $30^{\circledR}$ were submitted to a commercial laboratory, Cumberland Valley Analytical Services, Cumberland, MD., USA for in vitro determination of protein digestibility using the method described by Ross et al. [2]. These results were compared to the in vivo results described.

\section{Results and Discussion}

Results of the in vivo and in vitro tests are provided in Table 2. The rapidly soluble fractions, or A protein fractions were similar between the two methods of analyses, as were the determined rates of solubilization of the slow digesting fraction. Therefore the in vitro method appears to be quite adequate for the determination of the

\begin{tabular}{|ccccc} 
Table 2. Results of the in vivo and in vitro analyses $(\mathrm{n}=3)$. \\
\hline & $\underline{\text { In Vivo }}$ & \multicolumn{3}{l}{ In Vitro } \\
\hline Analysis & Mean & St. Dev. & Mean & St. Dev. \\
\hline Lysine, \% & 31.5 & 0.70 & 31.0 & 1.91 \\
Soluble fraction, A, \% & 8.33 & 1.99 & 8.86 & 2.31 \\
Rate of disappearance, Kd, \%/h & 2.64 & 0.07 & 2.43 & 0.56 \\
Total tract digestibility $^{1}$ & 84.4 & 6.57 & 75.9 & 5.24 \\
\hline
\end{tabular}

${ }^{1}$ Based on 1 sample in vivo and 3 samples in vitro. 
rapidly soluble protein fraction, as well as the prediction of the rate of ruminal disappearance of the slowly soluble fraction of this rumen protected lysine product.

Total tract digestibility was somewhat higher with the in vivo test than with the in vitro test. However, only one sample could be evaluated in vivo, and the values are the means for the two cows. The calculated total tract digestibility value was $80 \%$, and the values obtained in vivo and in vitro were both within the limits expected.

Very limited information is available regarding the intestinal digestibility of lipid coated, rumen protected lysine. Rossi et al. [5] compared rumen protected amino acids treated with different commercially available coatings using the mobile nylon bag technique. Triglycerides, fatty acids and calcium salts of fatty acids were determined to have digestibility values of $100 \%$ when used to ruminal protect lysine hydrochloride. In comparison, Wu et al. [6] using the same technique, determined that triglyceride protected lysine sulfate had a total tract digestibility of $86.7 \%$. These values compare most favorably with the in vivo results obtained in the current study (84.4\%). The in vitro results were somewhat lower at $75.9 \%$.

A more commonly used procedure is to assess the relative bioavailability of products, based on plasma amino acid concentrations [7]-[9]. This method required frequent blood sampling to divine changes in plasma concentrations of the protected amino acid, and computation of the area under the curve. While such a method may permit products to be compared to each other if analyzed at the same time, it does not provide a true value for total tract digestibility, and thus the in vitro method would be preferred from that point of view.

The in vitro method of protein digestibility of Ross et al. [2] was developed for the routine, consistent analysis of feed ingredients. These results show that the method can also provide accurate results for rumen protected amino acid products. The advantage to the in vitro method is that it is rapid, and less costly. While in vivo methods do not lend themselves to routine analysis, as might be required for new product development or quality control, the in vitro procedure fits these roles perfectly.

\section{Conclusion}

These results show that the in vitro method of Ross et al. [2] can be used to supply much needed values for solubility, rates of digestion and the total tract digestibility of rumen protected lysine products. Such results support the provision of accurate values that are required for feed formulation platforms, and will advance the acceptance of such products.

\section{Acknowledgements}

We are indebted to the dedicated staff at the Atlantic Dairy and Forage Institute for their efforts in generating these data.

\section{References}

[1] Rebouche, C.J. and Seim, H. (1998) Carnitine Metabolism and Its Regulation in Microorganisms and Mammals. Annual Review of Nutrition, 18, 39-61. http://dx.doi.org/10.1146/annurev.nutr.18.1.39

[2] Ross, D. A., Gutierrez-Botero, M. and Van Amburgh, M.E. (2013) Development of an In-Vitro Intestinal Digestibility assay for Ruminant Feeds. Proceedings of the Cornell Nutrition Conference, 190-202.

[3] FASS (2010) Guide for Care and Use of Agricultural Animals in Research and Teaching. 3rd Edition, Federation of Animal Science Societies, Champaign, IL.

[4] Vanzant, E.S., Cochran, R.C. and Titgemeyer, E.C. (1998) Standardization of In Situ Techniques for Ruminant Feedstuff Evaluation. Journal of Animal Science, 76, 2717-2729.

[5] Rossi, F., Maurizio, M., Francesco, M., Giovanna C. and Gianfranco, P. (2003) Rumen Degradation and Intestinal Digestibility of Rumen Protected Amino Acids: Comparison between In Situ and In Vitro Data. Animal Feed Science and Technology, 108, 223-229. http://dx.doi.org/10.1016/S0377-8401(03)00131-7

[6] Wu, Z., Bernard, J.K., Eggleston, E.B. and Jenkins, T.C. (2012) Ruminal Escape and Intestinal Digestibility of Ruminally Protected Lysine Supplements Differing in Oleic Acid and Lysine Concentrations. Journal of Dairy Science, 95, 2680-2684. http://dx.doi.org/10.3168/jds.2011-5203

[7] Rulquin, H., and Kowalczyk, J. (2003) Development of a Method for Measuring Lysine and Methionine Bioavailability in Rumen-protected Products for Cattle. Journal of Animal and Feed Sciences, 12, 465-474.

[8] Whitehouse, N.L., Brito, A.F., Crowther, A., Pereira, A.B.D., Schwab, C.G., Shinzato, I. and Miura, M. (2014) Validation 
of the Bioavailability of the Second Generation of AjiPro-L Using the In Vivo Plasma Lysine Response Method. Journal of Animal Science, 92, 753. (Abstract)

[9] Tucker, H., Miura, M., Shinzato, I. and Ballard, C.S. (2015) Comparative Bioavailability of Lysine in Three Commercially Available Rumen Protected Lysine Products Using the In Vivo Plasma Lysine Response Method. Journal of Dairy Science, 98, 743. (Abstract) 